\title{
Erratum to: Voltage-gated Sodium Channels and Blockers: An Overview and Where Will They Go?
}

\author{
Zhi-mei LI ${ }^{1}$, Li-xia $\mathrm{CHEN}^{2}$, Hua $\mathrm{LI}^{1}$ \\ ${ }^{1}$ Hubei Key Laboratory of Natural Medicinal Chemistry and Resource Evaluation, School of Pharmacy, Tongji Medical College, \\ Huazhong University of Science and Technology, Wuhan 430030, China \\ ${ }^{2}$ Wuya College of Innovation, Key Laboratory of Structure-Based Drug Design \& Discovery, Ministry of Education, Shenyang \\ Pharmaceutical University, Shenyang 110016, China
}

(C) The Author(s) 2020

\author{
Current Medical Science \\ https://link.springer.com/article/s11596-019-2117-0 \\ 39(6):863-873,2019
}

\begin{abstract}
The article "Voltage-gated Sodium Channels and Blockers: An Overview and Where Will They Go?", written by Zhi-mei LI, Li-xia CHEN, Hua LI, was originally published electronically on the publisher's internet portal on December 2019 without open access. With the author(s)' decision to opt for Open Choice, the copyright of the article is changed to (C) The Author(s) 2020 and the article is forthwith distributed under a Creative Commons Attribution 4.0 International License (https://creativecommons. org/licenses/by/4.0/), which permits use, sharing, adaptation, distribution and reproduction in any medium or format, as long as you give appropriate credit to the original author(s) and the source, provide a link to the Creative Commons license, and indicate if changes were made.
\end{abstract}

The original article has been corrected.

Corresponding authors: Li-xia CHEN, Hua LI 